\title{
Os manuais escolares, mídia de massa e suporte de representações sociais. 0 exemplo da Guerra Fria nos manuais franceses de História
}

Brigitte Morand*

\section{Resumo}

O manual escolar se constitui em um objeto cultural complexo e é, de fato, um significativo suporte de representações sociais. Sua elaboração se dá no cruzamento de lógicas institucionais, científicas, didáticas e editoriais. Este artigo tem como tema central as representações da Guerra Fria nos manuais escolares franceses de história e geografia, utilizados no ensino secundário entre os anos de 1959 a 2006, e foi desenvolvido a partir de um método que mescla abordagens quantitativas e qualitativas. Em nosso estudo, pudemos constatar que os manuais são cada vez mais ilustrados, e as imagens, assim como o texto que estrutura a lição, propõem uma narrativa articulada em torno da noção central de "partilha do mundo", na qual se encarnam os personagens, os acontecimentos, mas também as noções e os conceitos históricos. Essas imagens, fartamente divulgadas, funcionam igualmente em rede, uma vez que, na imprensa escrita quotidiana, veiculam muito mais uma memória coletiva do que um saber histórico.

\section{Palavras-chave}

manual escolar; mídia de massa; representações; imagens; Guerra Fria.
* Maître de Conférences en Sciences de l'Éducation (Laboratoire ACTé EA 4281). Directrice du département Didactique des Arts, Humanités et Sciences Sociales, IUFM d'Auvergne - Université Blaise Pascal, França.brigitte.morand@ univ-bpclermont.fr

Tradução de Carmen Lúcia Soares 


\title{
Textbooks: mass media and bedrock for social representations. The example of Cold War in the French history textbooks
}

\begin{abstract}
A textbook is a complex object at crossroad of different approaches, institutional, scientific, didactical, editorial, which all take part in its conception. In fact, the texbook is genuine bedrock for social representations that can be scrutinized using quantitative and qualitative methods. This paper analyses the representations of the Cold war in French history and geography textbooks for secondary education, published from 1959 to 2006. We show that textbooks are more and more illustrated through years. The pictures, as well as the texts of the lesson, provide a narrative based on the central notion of "the division of the World" embodies in characters, events and historical concepts as well. These pictures act as a network, exactly as they do in the daily press, and therefore they convey a collective memory rather than a historical knowledge.
\end{abstract}

Key words textbooks, mass media, representations, pictures, Cold War. 


\section{Introdução}

Os manuais escolares distanciam-se da ideia de serem simples suportes didáticos que se contentariam em transpor a pesquisa acadêmica, ou, ainda, um puro reflexo das demandas oficiais prescritas em um programa de ensino. Estudar a maneira como apresentam a história e, sem dúvida, a interpretam obriga-nos a considerar sua complexidade enquanto objetos culturais. Com efeito, o discurso presente nos manuais aquele que estrutura a lição propriamente dita, mas também todo o conjunto dos elementos que a constituem, tais como os aportes iconográficos; os textos; os mapas; as citações de referência - desafia as interpretações dos acontecimentos que não se resumem à explicação histórica - ela mesma uma interpretação -, mas remetem também às representações sociais. Mais exatamente, os manuais escolares refletem a concepção que os autores possuem, conscientemente ou não, do lugar da França no mundo, lugar esse construído ora com referências ao General De Gaulle, por exemplo, ora com aquelas ligadas à memória coletiva sistematicamente trabalhada por gerações de manuais escolares republicanos. Isso é particularmente verdadeiro para o tema da Guerra Fria, o qual servirá de exemplo à nossa demonstração. Em nosso trabalho de pesquisa, analisamos as representações da Guerra Fria nos manuais escolares franceses de história e de geografia destinados ao ensino secundário, no período compreendido entre 1959 e 2006.

Analisar os manuais escolares supõe, então, considerá-los em sua complexidade, assunto que será objeto da primeira parte deste artigo. Veremos, em seguida, como a análise por vezes quantitativa e qualitativa permite evidenciar as representações presentes nos manuais escolares e, em particular, o papel desempenhado pelas imagens, que desenham uma verdadeira "visão de mundo", no sentido próprio dessa expressão. Ao longo do período estudado, a iconografia se enriquece consideravelmente, e os manuais tornam-se verdadeiros "livros de imagens". Fotografias, mapas, cartazes funcionam em rede, respondem-se mutuamente e participam da elaboração de uma "visão de mundo", dessa vez em seu sentido figurado, ou seja, uma interpretação dos acontecimentos que oferece uma compreensão global da história, do lugar da França nessa história e no mundo. Finalmente, veremos que essa visão se aproxima muito mais de uma narrativa mítica que de uma história científica e que os manuais escolares, pelo seu funcionamento interno, se tornaram, nos dias de hoje, uma mídia de massa. 


\section{I - 0 manual escolar, um objeto cultural complexo}

O manual escolar obedece antes de tudo, evidentemente, a uma demanda institucional, seja ela nacional, como na França, seja oriunda de uma estrutura mais descentralizada, como é o caso da Alemanha (RFA). 0 programa, assim, define o conteúdo de história a ser ensinado e, nesse sentido, "normaliza" o discurso escolar. 0 manual escolar é, conforme as palavras de Alain Choppin (1992, ${ }^{1}$ p.164), “o principal vetor de valores que transmite a instituição escolar”, cujas escolhas "obedecem a objetivos políticos, morais, estéticos, ideológicos, quase sempre implícitos". Assim, uma vez mais reafirmamos que o manual escolar não é apenas suporte de transposição didática e que ele repercute igualmente, às vezes com bastante atraso, a transformação do saber científico e se faz eco de debates ideológicos e epistemológicos que nutrem a sua própria construção. 0 discurso dos manuais pode, assim, ser orientado por considerações ideológicas, tradições didáticas ou, ainda, pela memória individual dos autores, memória essa que guia a seleção e a interpretação dos acontecimentos. Mais que tudo, o manual escolar é um produto comercial - ao menos na França, onde o Estado não exerce qualquer controle sobre sua edição ou sua distribuição. Seu conteúdo é, pois, condicionado pelas considerações econômicas de sua produção, nas quais se mesclam as expectativas reais ou imaginadas dos professores que os prescrevem, considerações que podem inflectir sobre o discurso ali presente. Enfim, o manual escolar deve ser também "aceitável" por outros públicos potenciais, como os pais dos alunos e, mais globalmente, todas as pessoas sensíveis aos conteúdos de seu ensino. Isso é tão mais verdadeiro na França, onde, desde o século XIX, a história vem sendo utilizada como instrumento de construção da identidade nacional e onde esse ensino é, ainda hoje, julgado indispensável para a formação do cidadão. Assim, a história, na França, goza de certo prestígio, e esse sentimento faz com que cada nova reforma de seu ensino seja

1. N.T. Fizemos, quando possível, acréscimos no interior das referências no corpo do texto, para possibilitar a consulta pelo leitor.

2. N.T. Homem de rádio e televisão, Alain Decaux é um apaixonado pela história. Em 1957, ele criou o programa intitulado "A câmera explora o tempo ", que permaneceu até 1966 , seguido de outro que esteve no ar entre 1969 e 1988, denominado "Alain Decoux narra ». Ele também escreveu livros de vulgarização histórica e foi ministro da Francofonia entre 1988 e 1991, durante o segundo mandato de François Mitterrand. 0 artigo em questão foi publicado no Figaro Magazine, n. 10926, em 20/10/1979. acompanhada de acaloradas reações, por parte tanto dos professores, quanto da "sociedade civil" ou, ainda, dos historiadores. Dois exemplos permitem ilustrar o papel desempenhado pelo ensino de história na França. 0 primeiro deles diz respeito ao que sucedeu a uma reforma no ano 1979, a qual suprimia a ordem cronológica até então central na trama da narrativa histórica ensinada aos alunos. Naquele momento, Alain Decaux ${ }^{2}$ lançou um debate acalorado 
entre os intelectuais, publicando no Fígaro Magazine, de 1979, um artigo intitulado "Não ensinamos mais história às crianças". 0 outro exemplo, bem mais recente, refere-se às inúmeras reações, por parte dos historiadores, à reforma de 2010, que suprimiu a história no último ano do Liceu científico, a seção mais prestigiosa do Liceu na França³. Parece não haver dúvidas do quanto essas reações, aqui brevemente descritas, testemunham essa compreensão do lugar da história. Para concluir este item, lembremos que o conteúdo dos manuais foi, inúmeras vezes, questionado e acusado, por exemplo, de ser abertamente marxista. Todavia, é muito mais a sua elevada uniformidade - poderíamos, mesmo, dizer sua conformidade - que pudemos constatar em nossa pesquisa4.

Objeto “multipolar”, para retomar aqui a expressão de Nicolas Lucas (2001), o manual escolar é o resultado das diferentes lógicas que concorrem para sua elaboração (Figura 1). Longe de reproduzir um discurso neutro, ele é, ao contrário, o lugar onde se revelam as contradições ou as tensões entre os diferentes polos, constituindo-se no cruzamento de todas essas diferenças.

Figura 1-0 manual escolar, um objeto cultural complexo

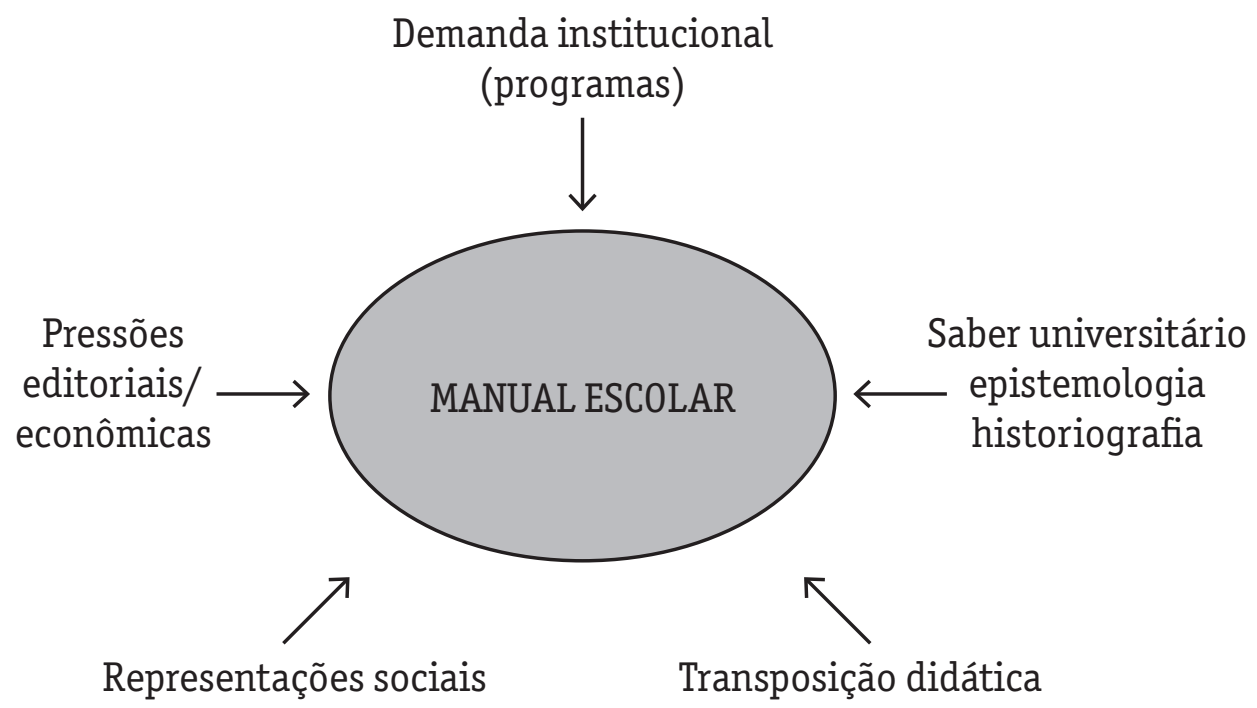


Constatamos isso inúmeras vezes, notadamente quando os autores adotam pontos de vista originais, contrários às prescrições dos programas. É por essa razão, entre outras, que não devemos considerar os manuais como simples reflexo do ensino ou do saber histórico dos alunos 5 . Optamos por analisá-los como um suporte privilegiado de estudo das representações sociais, definidas como "sistemas de interpretações sociais que regem nossa relação com o mundo e com os outros, que orientam e organizam as condutas e as comunicações sociais” (Jodelet, 1989, p. 31-62). Essa constatação, realizada durante nossa pesquisa sobre a imagem da Guerra Fria nessas obras, nos conduziu a elaborar, de maneira bastante pragmática, uma metodologia de análise que permite explicar seu modo de funcionamento nesses materiais pedagógicos.

\section{II - A análise dos manuais: uma metodologia que mescla o qualitativo e o quantitativo}

Os manuais escolares possuem a grande vantagem de constituir um corpus de fontes coerentes. Para analisá-los, escolhemos aquilo que Nicole Lucas (2001, p.60) denomina de "uma abordagem metodológica diversificada", aliando "a flexibilidade do método qualitativo" ao quantitativo, o que per-

3. N.T. Esse último ano do Liceu é denominado de Terminal. 0 que possui maior prestígio é o Terminal $S$, último ano do Licée Scientifique, curso que contempla um conjunto maior de disciplinas do campo das ciências da vida e das ciências exatas.

4. Apenas uma obra de todo o período estudado (1958-2006) se distingue verdadeiramente pela sua originalidade: trata-se daquela organizada por Serge Wolikov e publicada pela Messidor/Éditions Sociales em 1982. Escrita com o objetivo de propor uma leitura marxista da história do tempo presente, essa obra se coloca claramente como um "contramanual" e foi muito pouco utilizada nas salas de aula.

5. Os manuais escolares são reputados por se dirigirem, em primeiro lugar, aos alunos. Ora, é muito difícil saber aquilo que os alunos retêm verdadeiramente, e seriam apaixonantes os estudos sobre este tema.

6. Todas as obras analisadas pertencem ao Centro de Estudos de Documentação e de Pesquisa em Historia da Educação (CEDRHE), do Instituto Universitário de Formação de Professores de Montpellier-Universidade de Montpellier II. As datas correspondem àquelas dos programas, e não da edição dos manuais, em geral, ocorrida no ano seguinte. mite "determinar com exatidão as concordâncias, as noções ou os valores explícitos e implícitos [e] validar as comparações".

Mas, antes de analisar os discursos dos manuais escolares sobre a Guerra Fria, seria necessário avaliarolugarqueelaocupa emseu conteúdo deensino.

\section{0 peso da Guerra Fria nos manuais de história do curso secundário}

Para essa pesquisa, da qual este artigo é um pequeno recorte, foram analisados 152 manuais de história e de geografia (Figura 2), elaborados entre os anos de 1958 e 2006, e classificados em períodos, conforme os programas escolares ${ }^{6}$. Considerando a organização do currículo na França, eles são destinados ao ensino secundário, mais 
precisamente ao último ano do colégio, que atende alunos com cerca de 14 anos, e do último ano do Liceu, em que os alunos têm cerca de 17 anos.

Figura 2 - Lugar da Guerra Fria nos manuais de história do terminal, desde 1959

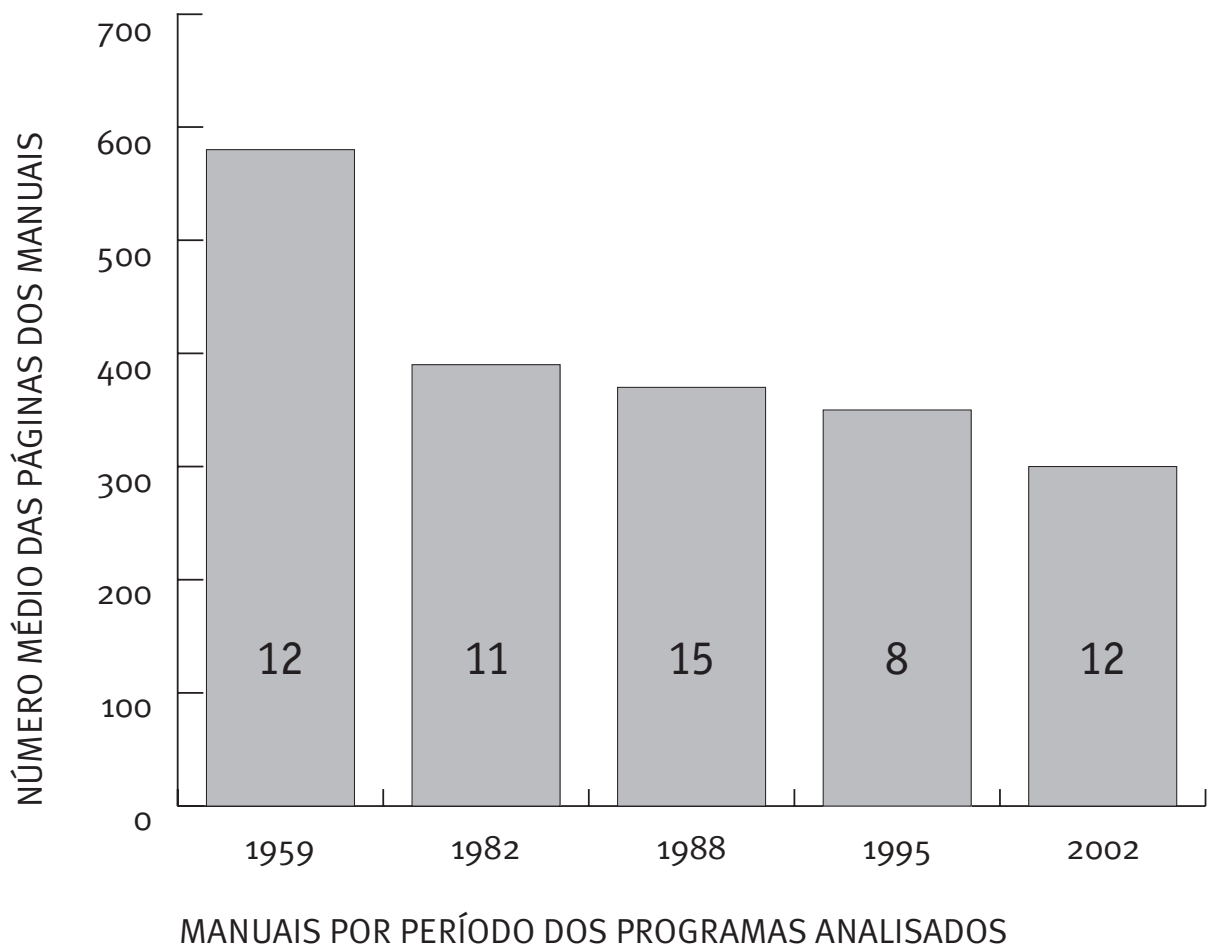

Cada período indicado na Figura 2 compreende as obras das editoras mais presentes em salas de aula, completadas pelas edições de menor repercussão. Estas últimas, entretanto, devem ser consideradas, uma vez que algumas delas alcançaram real sucesso no período estudado. A percepção das indicações dos programas é necessária, na medida em que, entre todas as lógicas presentes em sua elaboração, a prescrição oficial - que na França emana do Ministério da Educação Nacional - é determinante sobre o conteúdo dos manuais escolares. Entretanto, essa prescrição deixa uma margem de manobra importante, já que o Estado não exerce qualquer con- 
trole sobre as obras, nem antes, nem depois de sua edição. Os autores têm, portanto, total liberdade e, via de regra, adotam pontos de vista próprios, contrários às prescrições dos programas. Ocorre também que certos autores inovam e introduzem conceitos ou novos saberes que são, em seguida, adotados oficialmente em programas posteriores? ${ }^{7}$. Porém, embora os autores possuam grande liberdade para a elaboração dos manuais, a análise destes terá maior confiabilidade, se nós os classificarmos pelo período de cada programa, conforme podemos verificar na Figura 3.

Nosso objeto - a Guerra Fria - faz-se presente nos manuais de história no decorrer dos anos sessenta, quando os programas prolongam o estudo do século XX "até nossos dias", ou seja, a partir de 1969, para a classe de terceiro ano; e, a partir de 1982, para o último ano do Liceu (até o "tempo presente"). Desta data em diante, o programa de história estende o período estudado até o tempo presente dos alunos, ou seja, 1969 e 1982, respectivamente. O programa anterior destinado ao último ano do Liceu e datado de 1959 preconizava tratar os eventos de história mundial até o ano de 1945 e abordar, em seguida, o estudo das "civilizações do mundo contemporâneo", sob a influência de Fernand Braudel, inspirador desse programa, considerado, naquele momento, como revolucionário. Todavia, é possível trabalhar sobre as representações da Guerra Fria nos manuais escolares do programa de 1959, mesmo que este não especifique claramente o tema. Isso porque esses manuais propõem, inúmeras vezes, capítulos sobre as relações internacionais após 1945. Além do mais, os capítulos sobre a "civilização ocidental" e a "civilização soviética" são ricos de conteúdo e permitem determinar com exatidão as representações diretamente ligadas à visão da Guerra Fria ali presentes. Em 1982, dessa vez sob a influência dos historiadores do Institut de Histoire du Temp Présent, os programas reintroduzem a abordagem da então chamada "história acontecimento", compreendida como a história imediata. A introdução do "tempo presente" provoca um aumento relativo do lugar da

7. Assim acontece com o conceito de totalitarismo, que aparece nos manuais do Terminal a partir de 1983 - tendo raras ocorrências antes dessa data -, pouco depois que foram "redescobertas" as teses de Hannah Arendt pelos discípulos de Raymond Aron na França. Fortemente discutido pelos historiadores, 0 uso deste conceito se generaliza, todavia, notadamente nas obras da coletânea Berstein/Milza, antes de seu declínio no início dos anos de 1990, ao menos nos manuais do Terminal. Decorrente da prescrição explícita dos programas, este conceito se mantém, entretanto, nos manuais do terceiro e do primeiro.
Guerra Fria nos manuais, assim como uma maior extensão dos capítulos que tratam do tema nas reedições a partir de 1991, que passam a incluir os eventos ligados à queda do Muro de Berlim e ao desmantelamento da União Soviética. Em 1995, a diminuição relativa do tema se explica pela visão mais sintética dos acontecimentos impostos pelo programa, que visa à compreensão dos desafios 
ideológicos do conflito, em detrimento da narrativa detalhada dos acontecimentos; e pela reintrodução da Segunda Guerra Mundial no último ano do Liceu, diminuindo igualmente a parte consagrada ao conflito Leste-Oeste. Os programas de 2002 introduzem um capítulo sobre as democracias populares, provocando a intensificação do tema da Guerra Fria nos manuais escolares mais recentes.

\section{Uma abundância de imagens, mas sempre as mesmas.}

O mundo da Guerra Fria é absolutamente ilustrado e, entretanto, o "acervo" de imagens é singularmente restrito, ou seja, imutável ao longo do tempo: a mesma iconografia é empregada no mesmo contexto, ao longo do período estudado e em quase todos os manuais. A análise estatística permitiu calcular as frequências, ou seja, as porcentagens de manuais que utilizam - em cada período - tal expressão ou tal imagem e determinar com exatidão as inovações. A Figura 3, por exemplo, mostra a frequência, nos manuais do último ano do Liceu, do mapa que representa o raio de ação dos mísseis soviéticos instalados em Cuba. Até os anos de 1970, os mapas, ainda pouco frequentes nos manuais escolares, preenchem, sobretudo, uma função de localização; já os mapas analíticos ou conceituais se difundem somente bem mais tarde: entram nos manuais escolares do último ano do Liceu em $1983^{8}$, e sua origem não é decorrente de uma obra universitária, mas, sim, de uma obra jornalística de autoria de A. Fontaine ${ }^{9}$. É, aliás, o mapa publicado no Le Monde ${ }^{10}$ que os manuais propõem, em uma versão colorida, o que o torna mais legivel e muito mais atrativo. A partir do programa de 1989, o mapa se generaliza, provavelmente porque os editores se inspiram, como ocorre com frequência, na prática dos concorrentes. Este mapa é, desde então, presente em $70 \%$ a $80 \%$ dos manuais, tornando-se, assim, uma imagem-chave da Guerra Fria, do mesmo modo que a foto da Conferência de Yalta, ou, ainda, aquela do tanque soviético nas ruas de Praga em 1968, como veremos mais adiante.

8. 0 programa data de 1982 , os novos manuais de 1983 . 9. Historiador e jornalista, especialista nesta questão no Jornal Le Monde de 1947 a 1991.

10. N.T. Edição de 24 de outubro de 1962. 
Figura 3 - Frequência do mapa da crise de Cuba nos manuais escolares do terminal, a partir de 1959

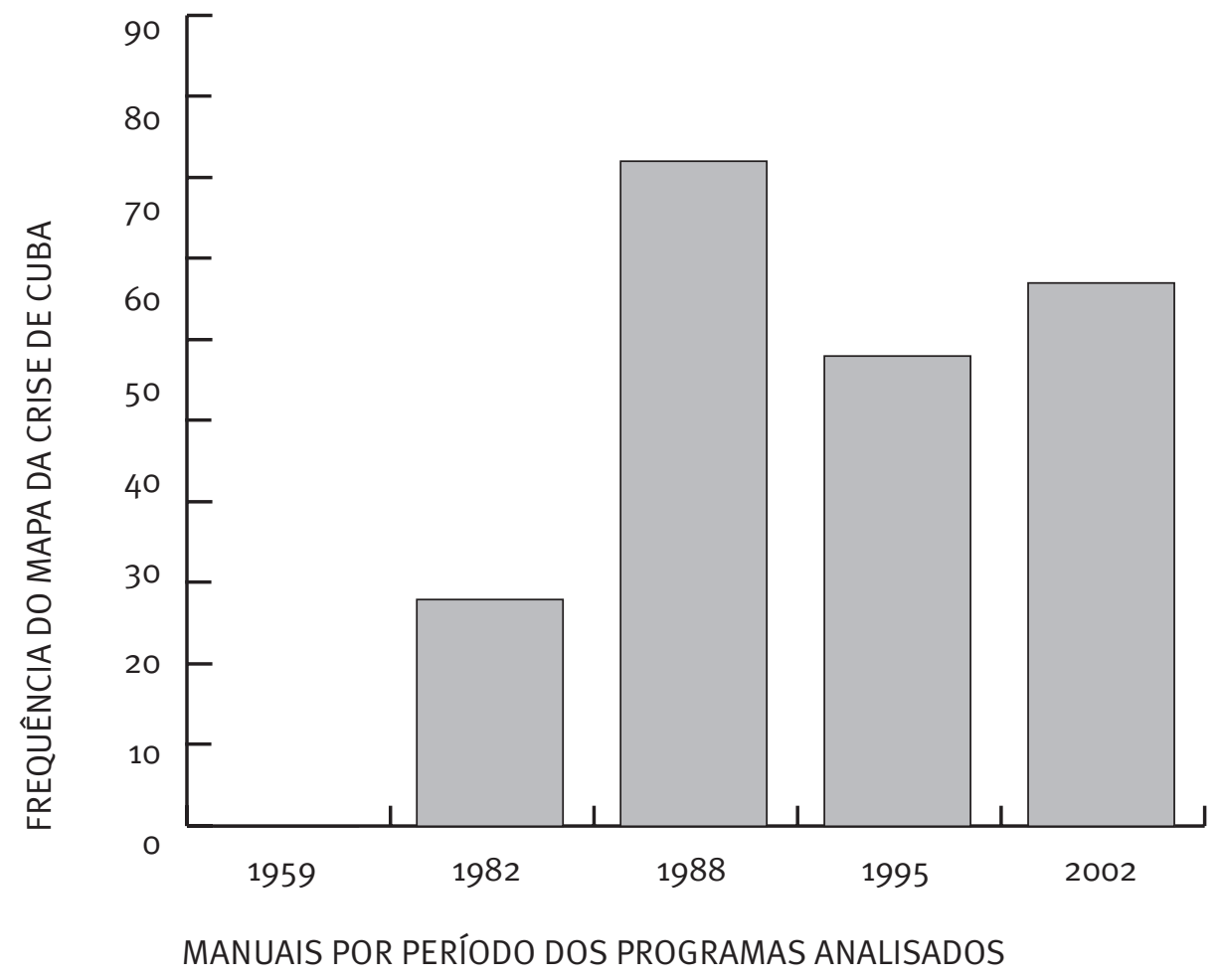

O cálculo das frequências revela-se, por vezes, insuficiente: ocorre, com efeito, que encontremos, em um mesmo manual, inúmeras representações de um mesmo objeto e, então, torna-se necessário calcular as médias. A Figura 4 representa o número médio de fotografias do Muro de Berlim nos manuais escolares de história do último ano do Liceu. Em 1959, apenas um livro propõe essa imagem, o que pode ser explicado pelo fato de que o programa desse ano não prevê abordar os acontecimentos depois de 1945 . Os editores não possuem, pois, qualquer obrigação de fazê-la figurar, e não seria anódino considerar que, além do mais, esses manuais foram redigidos na atmosfera da corrente dos anos de 1961 - para a maioria, então, antes da edificação do Muro. A foto é, contudo, introduzida somente nas edições ulteriores, cujo texto permanece imutável: até os anos de 1980, o Muro de Berlim, 
tema de que tratamos muito pouco na história, um pouco em geografia, praticamente não é mostrado. É necessário também acrescentar que a cultura da imagem não era ainda tão difundida como nos dias de hoje, e os autores dos manuais dos anos de 1960 sofriam menos a concorrência das grandes mídias de massa ${ }^{11}$. A fotografia, ao contrário, está presente em quase todos os manuais do programa de 1982, e, a partir de 1989, o número médio de fotos do Muro de Berlim chega quase a duas por manual. A ligeira baixa constatada em 1995 pode ser compensada pela redução de um desvio, em média, indicado aqui por um segmento mais ou menos longo acima de cada coluna, representando um período do programa. A alta espetacular do número médio de representações para o período do programa de 2002, ou seja, de 3,5 em média, e mais de 4 em certos manuais, explica-se pelo surgimento de fotografias da queda do Muro de Berlim e também pela presença de dossiês com um número bem maior de fotografias.

Figura 4 - Número médio de fotos do Muro de Berlim nos manuais do terminal, a partir de 1959

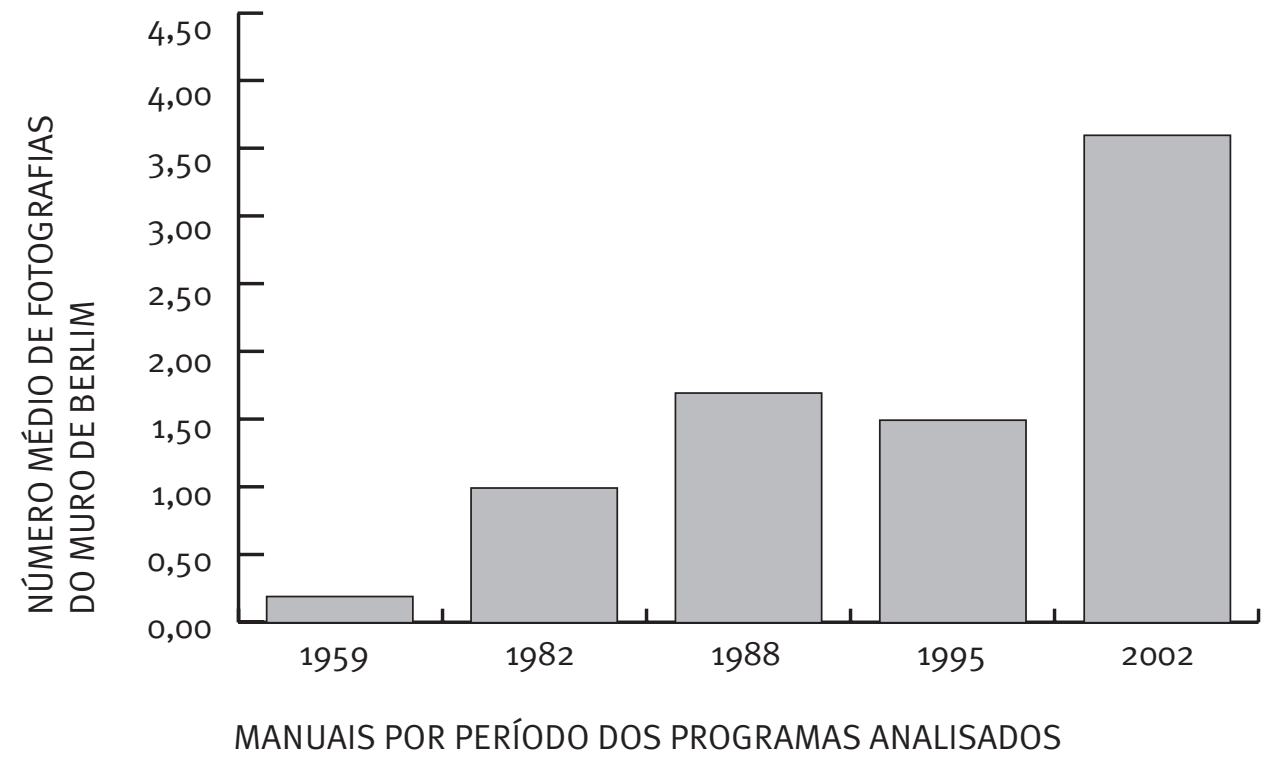

11. Nos dias de hoje, os editores competem para apresentar fotos que ilustrem a história mais imediata. 
Esta análise estatística por nós empreendida foi completada por um estudo qualitativo que tratou, em particular, da análise das relações texto-imagem ou das escoIhas de paginação, que são, na realidade, quase sempre verdadeiras "encenações" dos temas. É o caso da página dupla, na abertura de cada capítulo, nos manuais dos anos de 1970, em particular aqueles destinados ao colégio, o que se generaliza nos anos de 1990, incluindo também o Liceu. Nesse momento, os editores concorrem em engenhosidade, com a finalidade de "atrair o olhar" dos alunos ou dos professores. Essa página dupla inicial revela-se particularmente interessante para a introdução das imagens da Guerra Fria, pois ela defronta uma página com a outra, disposição que permite opor dois campos, um diante do outro. Assim, o manual do terceiro Bordas de 1980, em sua parte destinada à geografia, abre o capítulo "Os dois grandes" com uma página dupla em que aparecem as duas fotografias:

- página da esquerda: uma foto da Estátua da Liberdade;

- página da direita: uma foto da célebre escultura $O$ operário e a kolkhoziana.

A escolha das cores; o registro das imagens, similares nas duas fotos; o tamanho idêntico das estátuas, sem considerar suas dimensões reais - tudo ali sugere que a Guerra Fria é, na realidade, o “choque” de duas potências de pesos idênticos que, para além das diferenças ideológicas, possuem estranhas similitudes. Partilha do mundo entre dois “Grandes” de potência equivalente - tal é, com efeito, a mensagem sobre a Guerra Fria nos manuais escolares dos anos de 1960 a 1980.

\section{A Guerra Fria nos manuais escolares: uma narrativa mais próxima do mito que da história}

\section{A Guerra Fria: uma dolorosa recomposição da imagem do mundo}

Para além do desenrolar dos acontecimentos que marcam o antagonismo entre os blocos, o discurso dos manuais escolares sobre a Guerra Fria fornece, assim, matéria para uma verdadeira narrativa que utiliza personagens e se desenrola em meio a inúmeras peripécias, sem esquecer o necessário suspense. Como toda narrativa, ela imagina uma função explicativa e, em meio a uma verdadeira rede de representações, enriquecida e alimentada por conceitos universitários e ideológicos sucessivos, estrutura-se em torno da noção central de "partilha do mundo". E, também como toda narrativa, inicia por um acontecimento fundador dramático: a conferência de Yalta, que representa, conforme a expressão de Ray- 
mond Aron (1997, p. 550), “o mito do pecado original”. Este pecado original é a divisão da Europa em duas e o abandono de sua parte oriental aos soviéticos. Trata-se, para os franceses, de um duplo dilaceramento: não somente o golpe de uma Europa ferida em sua identidade, mas também e, talvez, sobretudo, o fato de a França - e, por extensão, a Europa - ter sido isolada da gestão dos assuntos mundiais. Yalta é, a um só tempo, um golpe imposto à Europa e uma partilha do mundo, "sem nós".

Esse mito foi igualmente veiculado por livros destinados ao grande público, como Yalta ou le partage du monde, de Arthur Conte, publicado em 1964. Esta representação de Yalta deve algo ao discurso dos manuais escolares? Nossa pesquisa não se dedicou a essa questão, e, assim, seremos bastante prudentes ao respondê-la. 0 que podemos dizer é que um significativo número de manuais escolares dos anos de 1960 a 1980 narra esse mito da partilha. A periodização do tema de Yalta nos manuais escolares apresenta-se da seguinte maneira (Figura 5):

- Dos anos de 1960 a 1980: a maioria dos manuais difunde o "mito da partilha”.

- A partir dos anos de 1980: os manuais se prendem à desconstrução do mito.

- Enfim,apartirdosanos de 1990, háuma relativa supressão do acontecimento.

Passamos de 0,75 páginas sobre o tema de Yalta, em média, nos anos de 1960-70, para mais de 2,25 páginas, em média, nos manuais dos programas de 1982. Como é preciso, agora, desconstruir o mito da partilha de Yalta, os manuais se empenham em tratar o tema desse ponto de vista. 0 texto que estrutura a lição propõe parágrafos bem desenvolvidos, com títulos bastante explícitos, como “Le partage de Yalta n’a pas eu lieu (1945)" (Belin, 1983) ou "Yalta ou le non-partage" (Magnard, 1983). Um exemplo de desconstrução do mito no manual Bordas (1983, p. 74) pode ser lido neste breve extrato:

“No Pós-Guerra, controvérsias vieram à tona sobre a significação de Yalta, sendo Roosevelt acusado de entregar uma parte da Europa aos soviéticos: de fato, mesmo que a espera entre os 'Três' dê lugar a ásperas barganhas, nenhum acordo concretiza uma nova partilha do mundo”. 
Figura 5 - Yalta nos manuais do terminal: do mito à história

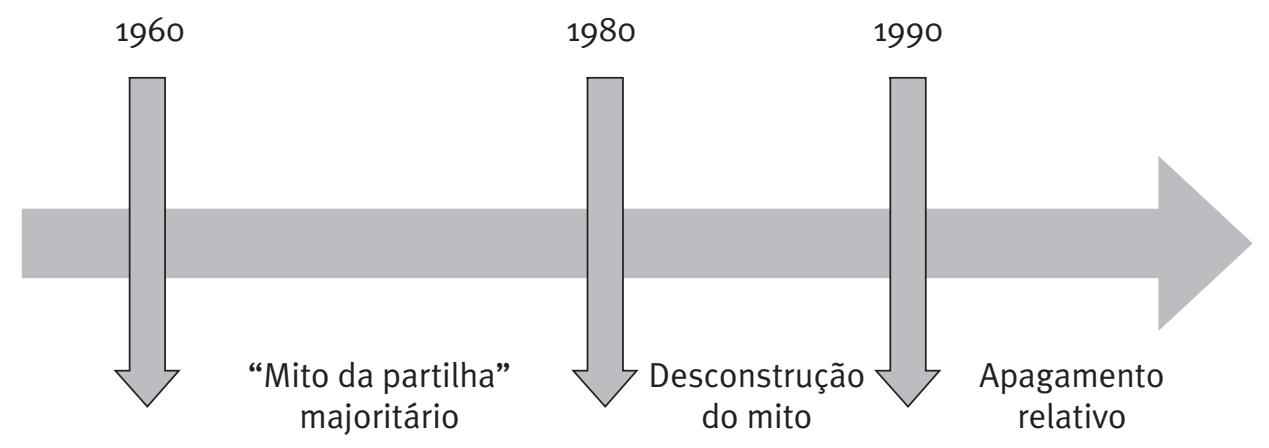

Finalmente, a partir dos anos de 1990, constatamos uma última modificação, com a relativa supressão de Yalta nos manuais: o tema não recebe mais que uma página por manual, e o texto que estrutura a lição também não lhe consagra mais que duas ou três linhas. De símbolo da "partilha do mundo", a Conferência de Yalta torna-se, progressivamente, a ilustração da perda da proeminência europeia nos assuntos mundiais. Mas persiste a ideia de que, desde esse período, as decisões são tomadas fora da Europa. A presença permanente da fotografia do encontro, mesmo nos manuais mais recentes, contribui também, muito provavelmente, para manter certa ambiguidade.

De fato, o "mito de Yalta" não ocupa mais seu lugar nos manuais, porém o "mito da partilha" não é totalmente abandonado: ele se reencarna em diferentes acontecimentos, tais como a crise de Cuba; em lugares como Berlim; ou em personagens da Guerra Fria. Para recusar essa tese, Raymond Aron (1997, p. 1233) assinalou, à época, que: "Como Yalta, o encontro de Washington parece se tornar lenda antes de entrar para a história". O que não impede que a grande maioria dos manuais dos anos de 1980 ilustre a détente/distensão por uma fotografia tirada durante a reunião de cúpula de Washington, onde se veem Nixon e Brejnev saudar a multidão do terraço da Casa Branca. "As duas potências estão de acordo sobre um ponto: a sorte do mundo se regulamenta entre eles, no diálogo direto de duas potências nucleares", comentam os autores do manual Nathan (1983, p. 223). A detente/distensão torna-se um novo avatar dessa partilha, representada, então, pelo “famoso telefone verme- 
Iho”. A “dupla americano-soviética” é uma ilustração da maneira pela qual funcionam as representações nos manuais escolares: Kennedy e Krouchtchev, Nixon e Brejnev, Reagan e Gorbatchev são as encarnações sucessivas e personificam as diferentes faces do conflito Leste-Oeste. Entretanto, trata-se sempre da mesma dupla, e, se os parceiros representam dimensões diferentes, estas coexistem e são tanto facetas do mesmo fenômeno, quanto variantes de um mesmo tema central: a partilha do mundo.

\section{Uma série de imagens que funcionam em rede}

0 "tanque soviético" que, a partir dos anos de 1980, encarna nos manuais escolares o totalitarismo soviético é outro avatar da partilha do mundo. 0 estudo quantitativo (Figura 6) mostra a utilização crescente da imagem desse tanque, que passa de uma foto por manual, em média, em 1983, para duas fotos e meia nos anos de 1990 e 2000.

Figura 6 - Imagens e estereótipos: o tanque soviético nos manuais escolares do terminal

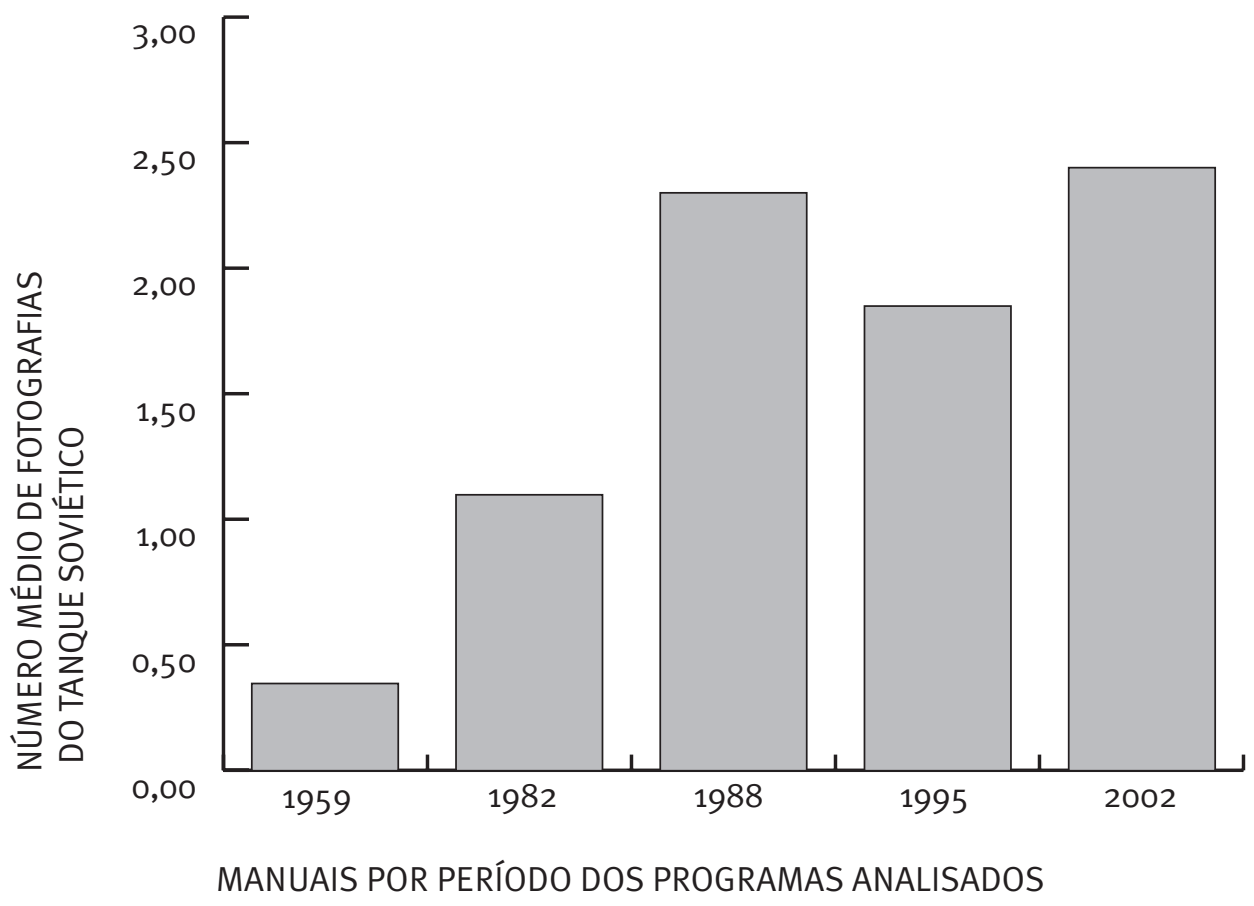


Um manual de 1983, O Magnard, destinado ao último ano do Liceu, intitulado, aliás, "La guerre des mondes", utiliza o tanque soviético até mesmo como símbolo cartográfico sobre um mapa, mostrando a repressão dos levantes populares nos países da Europa central. Para além dessa utilização, uma mesma fotografia - aquela da Praça Wenceslas, em Praga, que dá a impressão de um combate de rua - ilustra também as intervenções soviéticas em Berlim e Budapeste. Caberia sublinhar, ainda, que, ao contrário de Berlim e Budapeste, onde a população se sublevou de modo violento, em Praga isso não ocorreu e a manifestação foi pacífica. Este fato coloca um verdadeiro problema do ponto de vista didático: ensinar história aos alunos significa, em particular, ensiná-los a recolocar os acontecimentos em seu contexto, a restituir-lhes sua significação própria. 0 mesmo seria verdadeiro para a "dupla americano-soviética" citada anteriormente: para Khrouchtchev, como para Kennedy, os manuais escolares repercutem as imagens habilmente construídas para uso da imprensa e reproduzem as fotos das revistas desse período. A dupla Reagan-Gorbatchev é quase sempre representada por caricaturas, sendo estas últimas, em geral, bastante favoráveis aos soviéticos e bem pouco delicadas com os americanos. Consequentemente, pela utilização geral de fontes jornalísticas desde então, os desenhos da imprensa abundam, nos dias de hoje, nos manuais; e o desenhista Plantu ${ }^{12}$, assim, tornou-se indispensável para as ilustrações ali presentes. Os autores parecem supor que os rostos, largamente difundidos pela televisão, sejam bastante conhecidos dos alunos, para que uma caricatura seja suficiente para evocá-los. o que, sem dúvida, é verdadeiro para os personagens contemporâneos a eles, mas muito menos evidente, quando os acontecimentos e os personagens evocados thes são anteriores, mesmo que esse tempo seja apenas de alguns anos.

\section{Uma visão do mundo próxima da mídia}

12. N.T. "Jean Plantureux, Plantu, como é conhecido, nasceu em 23 de março de 1951 em Paris. Desenhista e cartunista especializado em sátira política, trabalha há 38 anos no Le Monde, e seus desenhos já foram objeto de diversas exposições no mundo todo. Na França, Plantu é visto como uma instituição. Sendo praticamente editoriais completos, seus desenhos buscam criar uma "excitação" gráfica, provocar um sorriso no leitor e também fazê-lo refletir." As informações desta nota foram extraídas de http://www.afbrasilia.org.br/agenda/plantu-release.pdf. Acesso em 17 de janeiro de 2012.
Na medida em que o papel do manual escolar é de fornecer aos alunos uma visão da história, se possível a mais próxima da história "científica", podemos considerá-lo como suporte de vulgarização. Mas os manuais são muito mais que isso, sobretudo porque a imprensa se tornou a principal fonte documental, ao menos sobre a história do século XX. As imagens que eles propõem privi- 
legiam os acontecimentos já fortemente midiatizados na época em que ocorreram, e os autores dos manuais adotam, mesmo, por vezes, um estilo "jornalístico", com o intuito de aproximar-se mais de seu público potencial. Trata-se, portanto, de responder às novas exigências pedagógicas, de adaptar-se a um público mergulhado em um oceano de imagens. Seria possível, então, afirmar que o mundo da Guerra Fria nos manuais escolares se parece, cada vez mais, com aquele difundido na mídia. A recorrência dessas imagens em um manual e outro e ao longo de todo o período estudado mostra também a pertinência da analogia entre o funcionamento da imprensa e o dos manuais escolares (Morand, 2008a, 2008b, 2011). A propósito das imagens do 11 de setembro, Clément Chéroux (2009, p. 13) descreveu o mesmo fenômeno no âmbito da imprensa escrita americana, o qual ele denomina de "diplopia”:

Aquele que, no dia seguinte ao 11 de setembro, tivesse um olhar, por pouco que fosse, atento às fotografias publicadas na imprensa internacional, poderia legitimamente se perguntar se ele mesmo não estaria pasmado, atônito de diplopia, considerando a quantidade de imagens que pareciam se desdobrar e se multiplicar. Não somente as mesmas fotografias se repetiam de um jornal a outro, mas cada uma entre elas parecia aumentar alguma coisa. A propósito dessas imagens imediatamente elevadas ao status de ícone, inúmeros jornalistas exprimiram, aliás, imediatamente, um sentimento de repetição constante, de algo já visto.

Aquilo que afirma Chéroux (2009, p. 46) acerca das imagens nos jornais coincide de maneira notável com o que nós havíamos observado nos manuais escolares, a começar pela padronização dos suportes enquanto tais,

provenientes das mesmas fontes, submetidos à mesma autoridade, obedecendo à mesma lógica do lucro, aplicando as mesmas receitas de marketing, etc., os jornais pertencentes aos grandes grupos se parecem cada vez mais, seus conteúdos de redação se padronizam.

Mas a analogia com a imprensa quotidiana é ainda mais forte, e, segundo Chéroux (2009), se as imagens do 11 de setembro - edifícios em chamas e nuvens de fumaça - marcaram a tal ponto os leitores, é porque elas faziam explicitamente referência 
a um acontecimento traumático já vivido pela nação americana, Pearl Harbor: "Parece evidente, nos dias de hoje, que inúmeras imagens do 11 de setembro publicadas na imprensa americana remetem, com efeito, ao ataque japonês sobre Pearl Harbor, repetindo as formas mais comuns de sua representação" (Chéroux, 2009, p. 60). As imagens dos manuais funcionam exatamente da mesma maneira: a fotografia da cúpula de Washington remete àquela de Yalta de maneira absolutamente exata e clara e, em um primeiro olhar, tudo nos parece como algo já visto. Para descrever esse fenômeno, Chéroux (2009, p. 77) propõe o termo "intericonicité"13, a partir do modelo da "intertextualidade":

Ele é válido tanto para as imagens como para os textos. 0s ícones dos atentados de New York constituem um excelente exemplo. Eles remetem do mesmo modo - senão mais - a outras imagens que à realidade do acontecimento do qual eles são o traço mais evidente.

Posicionando-se sempre no contexto do 11 de setembro, o autor interpreta esse recurso em relação à «intericonicité» como "uma maneira de sublinhar a gravidade dos acontecimentos [...] a reiteração dos esquemas visuais pertencentes ao passado deveria, assim, ajudar na compreensão e na interpretação do impacto histórico da situação" (Chéroux, 2009, p. 77). Isso parece, pois, antes de tudo, servir à história, o que, para Chéroux, é “uma primeira forma de interpretação” (Chéroux, 2009, p. 77). Mas qual tipo de interpretação? Trata-se, assim, de concluir que a história se repete? Evidentemente não, mas, ao contrário, “a história é repetida pelas mídias” (Chéroux, 2009, p. 77). A interpretação dos acontecimentos pelas mídias seria construída sobre uma concepção cíclica do tempo, como “o mito do eterno retorno". Ela não seria, desse modo, construída sobre a história, mas, sim, sobre a memória.

\section{Conclusão}

As imagens dos manuais e os textos que as acompanham fazem, pois, reviver a memória de Yalta e, por meio dessa conferência, o mito da partilha do mundo. A visão do mundo que eles oferecem é significativamente estável no curso do tempo e reduzida a algumas imagens-tipo. Ora, mais que a

13. N.T. Trata-se de um neologismo do autor; assim, propomos deixá-lo como aparece no texto original. questão da qualidade científica dos manuais, que são hoje, por sua uniformização, iguais sob este 
aspecto, esta constatação merece reflexão, pois se propõe aos alunos uma história que, tratando-se da escola, se quer razoável e o mais próxima possível daquela produzida pelos(as) historiadores(as). Se as imagens podem ajudar os alunos a adquirir uma primeira forma de conceitualização, elas podem ter, então, para além de sua atratividade, um real interesse didático. Mas elas contêm, também, quase sempre, estereótipos ${ }^{14}$, e é necessário estudá-los como tais, com os alunos, o que pode constituir um excelente meio de enriquecer o curso de história, mobilizando, assim, os interesses dos alunos. Assim, é indispensável que os professores sejam formados de modo a utilizar criticamente não apenas as imagens, mas o próprio manual escolar, esse instrumento de disseminação do saber que emprega métodos das "mídias de massa” em sua elaboração. Para finalizar, gostaríamos de sublinhar a necessidade de ensinar os alunos, nos dias de hoje, não apenas a decodificar o manual escolar, as imagens ali presentes, mas, também, a ler um jornal, a assistir televisão... ou navegar na Internet.

\section{Referências bibliográficas}

ARON, R. Les articles du Figaro. T3, La coexistence pacifique, 1997. Préface G.-H.

CHÉROUX, C. Diplopie. L'image photographique à l'ère des médias mondialisés: essai sur le 11-septembre 2001. Cherbourg: Le point du jour, 2009.

CHOPPIN, A. Les manuels scolaires: histoire et actualité. Paris: Hachette, 1992.

FONTAINE, A. Histoire de la guerre froide. T. 2, De la guerre de Corée à la crise des alliances. Paris: Fayard, 1967.

JEANNENEY, J-N. La profondeur du dérisoire. In: JEANNENEY, J-N. Une idée fausse est un fait vrai. Les stéréotypes nationaux en Europe. Paris: Odile Jacob, 2000. p. 9-14.

JODELET, D. Les représentations sociales: un domaine en expansion. In: JODELET, D. (Dir.). Les représentations sociales. Paris: PUF, 1989.

LEBRUN, M. Le manuel scolaire. Un outil à multiples facettes. Québec: Presses de l'Université du Québec, 2006.

LUCAS, N. Enseigner l'histoire dans le secondaire, manuels et enseignement depuis 1902. Rennes: PUR, 2001.

MORAND, B. La guerre froide dans les manuels

14. Jean-Noël Jeanneney (2000, p.13-14) sublinha que os estereótipos “... não flutuam sobre o nada. Razão pela qual eles podem nos informar de maneira bastante útil sobre as realidades concretas e afetivas que eles deformam sempre, camuflam quase sempre e, finalmente, revelam". 
scolaires français des années soixante à nos jours: une recomposition douloureuse de l'image de l'Europe et du monde. Tréma, n.29, p. 49-62, Mars 2008a.

MORAND, B. Les "Deux Grands " et la mise en pages de la guerre froide dans les manuels français depuis les années soixante-dix: partage du monde et stéréotypes. In: LUCAS, N.; MARIE, V. De la manipulation des images dans les classes. Paris: Le Manuscrit, 2008b. p. 73-92.

MORAND, B. Questions on the comparative method of European and U.S. textbooks: The example of the Cold War and the Berlin blockade. Yearbook of the International Society of History Didactics, 2011.

Recebido em 29 de março de 2012 e aprovado em 11 de maio de 2012. 